\title{
Innocent victims of passive smoking: An institutional experience.
}

1. MBBS, M.Phil Physiology Assistant Professor Physiology Al-Aleem Medical College.

2. DPT

Gulab Devi Institute of Physiotherapy, Lahore.

3. MBBS, M.Phil Physiology Assistant Professor Physiology Independent Medical College, Faisalabad.

4. MBBS, FCPS Physiology Assistant Professor Physiology Al-Aleem Medical College.

5. MBBS, M.Phil Physiology Assistant Professor Physiology Fatima Jinnah Medical University.

6. MBBS, FCPS Physiology

Assistant Professor Physiology

Niazi Medical \& Dental College.

7. MBBS

Medical Officer

King Edward Medical University,

Mayo Hospital, Lahore.

Correspondence Address:

Dr. Muhammad Hashim Ghouri

68-3A, Street 6, Askari Heights 1

Sector B Askari 11 Lahore.

hashim.ghouri@gdec.edu.pk

Article received on:

15/05/2020

Accepted for publication:

$26 / 08 / 2020$

\section{INTRODUCTION}

Passive smoking (also known as second hand smoking or SHS) is chiefly the consequence of the exposure of a nonsmoker to tobacco smoke in a closed environment, the so called Environmental Tobacco Smoke (ETS). Two main sources of ETS include the foremost stream (exhaled smoke of the smoker) and the side stream (smoke emitted from the lit end of the cigarette) smoke. ${ }^{1}$ Tobacco is a plant that belongs to Solanaceae family and its history dates back to 600-900AD. The Native Americans used tobacco for smoking in pipes, which was intended for medical reasons as well as on special religious event. First time it was harvested to earn money in North American state of Virginia. After picking it is dried and it needs to be grinded before use. Tobacco smoke is a

Key words:
Wardah Anwar', Muhammad Hashim Ghouri², Maria Anwar ${ }^{3}$, Ambreen Anjum, Maryam Rao ${ }^{5}$,

ABSTRACT... Objectives: To determine the impact of exposure to second hand smoking on fetal birth weight and length. Study Design: Comparative Cross Sectional study. Setting: Physiology Department of Shaikh Zayed Postgraduate Medical Institute. Period: December 2015 to May 2016. Material \& Methods: Non-probability convenience sampling was used to collect data from 120 women and their neonates, who were further divided in four equal coups based on level of exposure to second hand smoking. A self-administered questionnaire was used to collect data regarding level of exposure of mothers, while weight and length of +0.50 , in group- 2 was $3.00+0.28$ in group- 3 was $2.92+0.48$ and in group-4 was $2.66 \pm$ 0.41 . The p-value calculated by one way ANOVA was 0.001 which shows that birth weight was significantly different in all the groups. Mean birth weight of neonates showed inverse relation with exposure of the mothers. Mean length (cm) of neonates in group-1 was $49.30 \pm 1.70$ ( 2 was $48.77 \pm 1.47$, in group-3 was $49.40 \pm 2.12$ and in group-4 was $48.53 \pm 1.65$ th was seen that there was no significant difference in length of neonates belonging to different abilities and developmental milestones of neonates. Awareness should be made in society in

Community Health Education, Development \& Growth, Environmental Tobacco Smoke, Infant Health, Maternal Health, Passive Smoking, Public Health, Pulmonary Complications,

Article Citation: Anwar W, Ghouri MH, Anwar M, Anjum A, Rao M, Tabassum S, Ali MM. Innocent victims of passive smoking: An institutional experience. Professional Med J 2020; 27(12):2676-2680. https://doi.org/10.29309/TPMJ/2020.27.12.4819

mixture of particles and gases including nicotine, polycyclic hydrocarbons, Carbon mono-oxide and nitrogen oxide; with nicotine being the most harmful. ${ }^{1}$ These compounds also increase the risk of morbidity and mortality in non-smoking infants, children and adults. Twenty two thousand hospitalizations have been reported each year because of second hand smoking. ${ }^{1}$ Passive smoking imparts negative effects not only on birth weight ${ }^{1}$ and neonatal health, but it is also a critical risk factor for respiratory diseases in children. ${ }^{2}$ Nicotine crosses the placental barrier, with a study suggesting that concentration of nicotine is slightly more in amniotic fluid and fetal serum as compared to maternal serum. ${ }^{3}$

In humans, birth weight of fetus is affected 
by factors that affect the development during intrauterine period. ${ }^{3}$ Birth weight is very important and significant as it is associated with likelihood of mortality and morbidity. Not only does it affect the survival of the infant but also it holds an important place in measuring the developmental milestones of infants. Birth weight and infant mortality are thought to be inversely related. ${ }^{4}$ Birth weight is an important factor as it is seen that out of seven fundamental goals described by united nation birth weight holds one-third space in "A world fit for children" program. ${ }^{5}$ Some studies suggested that nicotine exposure decreases the intelligence quotient (IQ) of those babies who were exposed to it in their prenatal life. ${ }^{6}$ The exposure of fetus to nicotine either actively or passively causes anorexia. ${ }^{7}$ Blood supply to the placenta is also reduced due to the production of catecholamine by the action of nicotine on the adrenal gland and nerve cells. ${ }^{8}$ It has been established that nicotine exposure has an endocrine like effect on the development of the placenta. This endocrine effect is because of the effect of Nicotine on altering the enzymatic activity as well as the metabolism of proteins. ${ }^{9}$

Low birth weight in developed countries stands at $7 \%$ whereas figure in developing countries is very alarming at $16.5 \%$, with the highest in South Asia recorded as $27 \% .{ }^{10}$ Pakistan has alarmingly large number of LBW cases reported to be $12-25 \% .{ }^{11}$ Length of the baby is associated with his/her height at adulthood. This association is stronger in babies who are born between 39 to 41 weeks of gestation, whereas less association in seen in preterm. ${ }^{12}$ Smoking is a hazard, which is prevailing in our region; unfortunately its effects are not limited to one who is smoking but also extend to the surrounding people. The rationale of this study was to determine the impact of exposure to second hand smoking on fetal birth weight and length. Most of the previous studies have only discussed comparison between smokers, non-smokers and passive smokers, whereas our study has discussed different groups of passive smokers.

\section{MATERIAL \& METHODS}

A comparative cross-sectional study was conducted in the Physiology Department of Shaikh Zayed Postgraduate Medical Institute, in collaboration with Gynecology and Obstetrics Department of Shaikh Zayed Hospital, Lahore and with Gynecology and Obstetrics Department of Sir Ganga Ram Hospital, Lahore for duration of 6 months. Sample of 120 females was chosen by non-probability convenience sampling, with the inclusion criteria being normal pregnancy of 37 to 40 week without any gynecological problems or any family history of gynecological problem; age group 20 to 35 years having a single pregnancy. Females with diabetes, hypertension, renal, respiratory or cardiovascular disease, HIV infection, multigravidas, history of complicated pregnancies (due to anemia, IUGR), smoking mothers, and drug/alcohol addicts were excluded from the study. All included females had births at full term (38+ weeks). The study population was divided into 4 equal groups: group 1 (control group), with no exposure of second hand smoking; group 2 with exposure less than 6 cigarettes/day; group 3 with exposure 6-10 cigarettes/day; and group 4 with exposure $>10$ cigarettes/day.

The study was conducted after approval from The Ethical Committee. Pregnant females fulfilling the inclusion criteria were requested for their informed written consent for participation of their neonates in the research project. A selfadministered questionnaire was used to collect information regarding the tobacco exposure in the study group. Personal data including name, age and weight at first visit was recorded from their antenatal cards. Height, education and employment status of mother was also recorded. For neonates, weight was measured in kilogram by infant.

\section{RESULTS}

Mean age of mothers in Group 1 was $25.77 \pm 4$, in Group 2 was $25.27 \pm 3.69$, in Group 3 was 24.70 \pm 3.92 and in Group 4 was $24.90 \pm 3.92$ years. The mean age in each group was statistically the same.

Mean BMI in Group 1 was $23.94 \pm 3.88$, in Group 2 was $22.81 \pm 2.88$, in Group 3 was $23.85 \pm 3.23$ 
and in Group 4 was $22.89 \pm 3.13$ years. The mean $\mathrm{BMI}$ value in each group was also statistically same.

\begin{tabular}{|c|c|c|c|c|c|c|}
\hline & & Mean & S.D & Minimum & Maximum & P-Value \\
\hline \multirow{5}{*}{ Weight(kg) } & $\mathrm{G}-1(\mathrm{n}=30)$ & 3.31 & 0.50 & 2.30 & 4.40 & \multirow{5}{*}{0.001 * } \\
\hline & $\mathrm{G}-2(\mathrm{n}=30)$ & 3.00 & 0.28 & 2.40 & 3.50 & \\
\hline & G-3(n=30) & 2.92 & 0.48 & 2.00 & 4.00 & \\
\hline & $\mathrm{G}-4(\mathrm{n}=30)$ & 2.66 & 0.41 & 2.00 & 3.50 & \\
\hline & Total $(n=120)$ & 2.97 & 0.48 & 2.00 & 4.40 & \\
\hline
\end{tabular}

Table-I. Comparison of neonatal weight $(\mathrm{kg})$ in all study groups

* The mean difference is significant at the 0.05 level

\begin{tabular}{|c|c|c|c|c|c|c|}
\hline & & Mean & S.D & Minimum & Maximum & P-Value \\
\hline \multirow{5}{*}{ Length $(\mathrm{cm})$} & $\mathrm{G}-1(\mathrm{n}=30)$ & 49.30 & 1.700 & 45.00 & 53.00 & \multirow{5}{*}{0.173} \\
\hline & $\mathrm{G}-2(\mathrm{n}=30)$ & 48.77 & 1.470 & 43.00 & 50.00 & \\
\hline & $\mathrm{G}-3(\mathrm{n}=30)$ & 49.40 & 2.120 & 45.00 & 56.00 & \\
\hline & $\mathrm{G}-4(\mathrm{n}=30)$ & 48.53 & 1.650 & 45.00 & 52.00 & \\
\hline & Total $(n=120)$ & 49.00 & 1.770 & 43.00 & 56.00 & \\
\hline
\end{tabular}

Table-II. Comparison of neonatal length $(\mathrm{cm})$ in all study groups

* The mean difference is significant at the 0.05 level

\begin{tabular}{|l|c|c|c|c|}
\hline & Group 1 & Group 2 & Group 3 & Group 4 \\
\hline Incidence & $\begin{array}{c}1 / 30 \\
(3.33 \%)\end{array}$ & $\begin{array}{c}1 / 30 \\
(3.33 \%)\end{array}$ & $\begin{array}{c}3 / 30 \\
(10.0 \%)\end{array}$ & $(30 \%)$ \\
\hline Weight of LBW babies & 2.3 & 2.4 & $2.0,2.0,2.3$ & $\begin{array}{c}2.0,2.0,2.0,2.0,2.2,2.3, \\
2.4,2.4,2.4\end{array}$ \\
\hline
\end{tabular}

Table-III. Incidence of low birth weight $(\mathbf{k g})$ babies in different groups

\section{DISCUSSION}

Passive smoking is silently affecting the population. Most of the people are unaware of the hazards it is causing; especially they are not aware of the fact that the developing fetus is also being affected.

Pregnant women in our society are exposed to cigarette smoke not merely by indoor smoking husband but also the other housemates. This is due to the fact that we live in joint families with father in law, brother in law or other elders living together. Mostly they share same common sitting area and sometimes the same room. However, it was noted in the study that the contribution of SHS exposure by the husband was the most. Our study did not find the association of length of baby with SHS exposure.

According to our study birth weight reduces in each group with maximum reduction of 310 grams between non exposed and exposed mothers. A study in which hair nicotine levels were measured and it was seen that women having nicotine more than $0.35 \mathrm{ng} / \mathrm{ml}$ delivered one week earlier and their neonates had decrease of birth weight by 200-300 g. ${ }^{13}$ Another study suggested that there was lowering of adjusted mean birth weights by $36 \mathrm{~g} .{ }^{14}$ In a similar study done by Goel and Radotrait, it was seen that SHS causes the mean birth weight to reduce by $138 \mathrm{~g} \cdot{ }^{15}$ Exposure of mother to environmental smoke leads to poor development of placenta eventually leading to reduced blood flow. This in turn leads to babies with lower than normal birth weight. ${ }^{16}$

In our study no significant effect of SHS was seen on fetal length. Similar findings were seen in a study which measured the fetal outcomes after SHS exposure during pregnancy. In this study, length of the neonates born to mothers exposed to passive smoking was shorter than those who were born to non-exposed mothers yet the difference was not statistically significant. ${ }^{17}$ These 
findings do not negate the harmful effects of passive smoking, as multiple studies have shown a decrease in length of baby with increasing exposure. A study done in Saudi Arab reported a decrease in mean length of the neonates to be shorter by $0.261 \mathrm{~cm}$ in comparison to the infants born to unexposed mothers. ${ }^{18}$

The overall incidence of LBW in our study was found to be $11.66 \%$, the incidence of LBW in women with no SHS exposure was $3.33 \%$ and among exposed mothers was $14.4 \%$. The total incidence of LBW in a Malaysian study ${ }^{19}$ was $7.5 \%$, which was lower than our study and the incidence $(10 \%)$ of LBW in the general Malaysian population as estimated by UNICEF. ${ }^{20}$ The incidence of LBW in women with SHS exposure was $10 \%$, compared to $4.7 \%$ among non-exposed women. The incidences of our study were found to be lower than those from a study among the Indian population, in which the incidence was $31.9 \%$ among the exposed and $17.2 \%$ among the non-exposed group. ${ }^{21}$ This might be explained by the presence of many other risk factors in the Indian population. Another study in Asia also observed $7.7 \%$ incidences of LBW in the nonexposed group and $12.6 \%$ incidences in the SHS exposed group. ${ }^{21}$

\section{CONCLUSION}

Second hand smoke is dangerous for health. It not only affects the non-smokers but also the innocents who have not even stepped in the world. Not only their birth weight is affected but also the intellectual abilities and developmental milestones are also slowed down. Awareness should be made in public. Laws do exist which prohibit smoking in public areas but they are not implemented properly.

\section{RECOMMENDATIONS}

1. Awareness of SHS hazards should be made publicly; especially pregnant mothers should be advised to take utmost care to avoid exposure not only to active smoking but also to SHS.

2. Family members who smoke actively should try to smoke outside their house or at a distance from non-smoking members of their family, especially at a distance from expecting female members.

3. More research needs to be conducted to study other aspects of second hand smoking. Copyright@ 26 Aug, 2020.

\section{REFERENCES}

1. England LJ, Kendrick JS, Gargiullo PM, Zahniser SC, Hannon WH. Measures of maternal tobacco exposure and infant birth weight at term. American journal of epidemiology. 2001 May 15; 153(10):954-60.

2. Jedrychowski W, Galas AS, Flak E, Jacek R, Penar A, Spengler J, Perera FP. Increased burden of respiratory disease in the first six months of life due to prenatal environmental tobacco smoke: Krakow birth cohort study. Early Child Development and Care. 2007 May 1; 177(4):369-81.

3. Melve KK, Skjaerven R. Birthweight and perinatal mortality: Paradoxes, social class, and sibling dependencies. International journal of epidemiology. 2003 Aug 1; 32(4):625-32.

4. Balaji K, Sankar S, Nandagopal B. Low birth weight of newborns: Magnitude of the problem seen in a 100 bed hospital of a rural area in Vellore district, Tamil Nadu (India). Indian journal of community medicine: official publication of Indian Association of Preventive \& Social Medicine. 2010 Apr; 35(2):362.

5. Blanc AK, Wardlaw T. Monitoring low birth weight: An evaluation of international estimates and an updated estimation procedure. Bulletin of the World Health Organization. 2005; 83:178-85d.

6. Weitzman M, Byrd RS, Aligne CA, Moss M. The effects of tobacco exposure on children's behavioral and cognitive functioning: Implications for clinical and public health policy and future research. Neurotoxicology and teratology. 2002 May 1; 24(3):397406.

7. De Morentin PB, Whittle AJ, Fernø J, Nogueiras R, Diéguez $C$, Vidal-Puig $A$, López M. Nicotine induces negative energy balance through hypothalamic AMP-activated protein kinase. Diabetes. 2012 Apr 1; 61(4):807-17.

8. Duncan JR, Garland M, Stark RI, Myers MM, Fifer WP, Mokler DJ, Kinney HC. Prenatal nicotine exposure selectively affects nicotinic receptor expression in primary and associative visual cortices of the fetal baboon. Brain Pathology. 2015 Mar; 25(2):171-81. 
9. Jauniaux E, Burton GJ. Morphological and biological effects of maternal exposure to tobacco smoke on the feto-placental unit. Early human development. 2007 Nov 1; 83(11):699-706.

10. Wardlaw TM, editor. Low birth weight: Country, regional and global estimates. Unicef; 2004.

11. Khan N, Jamal M. Maternal risk factors associated with low birth weight. J Coll Physicians Surg Pak. 2003 Jan;13(1):25-8. PMID: 12685971.

12. Eide MG, Øyen N, Skjœrven R, Nilsen ST, Bjerkedal T, Tell GS. Size at birth and gestational age as predictors of adult height and weight. Epidemiology. 2005 Mar $1: 175-81$.

13. Ashford KB, Hahn E, Hall L, Rayens MK, Noland M, Ferguson JE. The effects of prenatal secondhand smoke exposure on preterm birth and neonatal outcomes. Journal of Obstetric, Gynecologic \& Neonatal Nursing. 2010 Sep 1; 39(5):525-35.

14. Ward C, Lewis S, Coleman T. Prevalence of maternal smoking and environmental tobacco smoke exposure during pregnancy and impact on birth weight: Retrospective study using Millennium Cohort. BMC public health. 2007 Dec 1; 7(1):81.

15. Goel P, Radotra A, Singh I, Aggarwal A, Dua D. Effects of passive smoking on outcome in pregnancy. Journal of postgraduate medicine. 2004 Jan 1; 50(1):12.
16. Andres RL, Day MC. Perinatal complications associated with maternal tobacco use. In Seminars in Neonatology 2000 Aug 1 (Vol. 5, No. 3, pp. 231-241). Elsevier.

17. Swidan RA. Effect of secondhand smoke exposure during pregnancy on anthropometric measurements of term infants. Iraqi Journal of Community Medicine. 2015; 28(1):49-55.

18. Wahabi HA, Alzeidan RA, Fayed AA, Mandil A, Al-Shaikh $G$, Esmaeil SA. Effects of secondhand smoke on the birth weight of term infants and the demographic profile of Saudi exposed women. BMC public health. 2013 Dec; 13(1):341.

19. Bachok NA, Salinah O. The effect of second-hand smoke exposure during pregnancy on the newborn weight in Malaysia. The Malaysian journal of medical sciences: MJMS. 2014 Mar; $21(2): 44$.

20. UNICEF. The state of the world's children 2003. Unicef; 2002.

21. Khader YS, Al-Akour N, AlZubi IM, Lataifeh I. The association between second hand smoke and low birth weight and preterm delivery. Maternal and child health journal. 2011 May 1; 15(4):453-9.

\section{AUTHORSHIP AND CONTRIBUTION DECLARATION}

\begin{tabular}{|c|c|c|c|}
\hline Sr. \# & Author(s) Full Name & Contribution to the paper & Author(s) Signature \\
\hline 1 & Wardah Anwar & $\begin{array}{l}\text { Principal investigator, Data } \\
\text { collection, Study design \& Concept. }\end{array}$ & Wardah \\
\hline 2 & M. Hashim Ghouri & $\begin{array}{l}\text { Manuscript writing \& Editing, } \\
\text { Correspondence. }\end{array}$ & 4.5 \\
\hline 3 & Maria Anwar & Interpretation of Data for work. & Maria Anwar \\
\hline 4 & Ambreen Anjum & Literature review. & Anyium \\
\hline 5 & Maryam Rao & Data collection. & Maryam Rao \\
\hline 6 & Saima Tabassum & Statistical analysis. & Saina \\
\hline 7 & M. Mohsin Ali & Manuscript review \& Final editing. & Orohum Sti \\
\hline
\end{tabular}

